\title{
A STUDY ON POSITION OF INFRAORBITAL FORAMEN
}

\section{Shaik Hussain Saheb ${ }^{1}$, Shruthi B.N ${ }^{* 2}$, Pavan P Havaldar ${ }^{3}$.}

${ }^{1}$ Department of Anatomy, JJM Medical College, Davangere, Karnataka, India.

*2 Department of Anatomy, Rajarajeswari Medical College and hospital, Bangalore, Karnataka, India.

${ }^{3}$ Department of Anatomy, Gadag institute of medical sciences, Gadag, Karnataka, India.

\section{ABSTRACT}

Background: The infraorbital foramen is located on the maxillary bone about $1 \mathrm{~cm}$ inferior to the infraorbital margin. The infraorbital nerve and vessels are transmitted through this foramen. The infraorbital nerve, the continuation of the maxillary or second division of the trigeminal nerve, is solely a sensory nerve. It traverses the inferior orbital fissure into the inferior orbital canal and emerges onto the face at the infraorbital foramen. It divides into several branches that innervate the skin and the mucous membrane of the midface, such as the lower eyelid, cheek, lateral aspect of the nose, upper lip, and the labial gum.

Materials and Methods: Total 300 skulls were used for this study, the following mesearements were recorded, mean distance between the infra orbital foramen and the infra orbital margin on right and left side and average of it. The mean distance between the infra orbital foramen and the piriform aperature on right and left side measured and average of it also recorded. The mean distance between infra orbital foramen and the anterior nasal spine on right and left side measured. The transverse and vertical diameter also measured.

Results: Total 300 skulls were used for this study, the results were the mean distance between the infra orbital foramen and the infra orbital margin was $8.48 \pm 1.92 \mathrm{~mm}$, on right side it was $8.72 \pm 2.16 \mathrm{~mm}$ and $8.20 \pm 1.92 \mathrm{~mm}$ on left. The mean distance between the infra orbital foramen and the piriform aperture was $19.35 \pm 3.26 \mathrm{~mm}$, on right side it was $19.10 \pm 3.42 \mathrm{~mm}$ and $19.56 \pm 3.26 \mathrm{~mm}$ on left. The mean distance between infra orbital foramen and the anterior nasal spine on right was $34.86 \pm 6.73 \mathrm{~mm}$ and left was $36.12 \pm 3.72 \mathrm{~mm}$ and total average was $35.51 \pm 3.75 \mathrm{~mm}$. The transverse diameter was $3.16 \pm 0.96 \mathrm{~mm}$ and vertical diameter was $3.03 \pm 0.72 \mathrm{~mm}$.

Conclusion: The knowledge of infraorbital foramen may be helpful in blocking of nerve passing through it for surgical purpose.

KEY WORDS: Infraorbital foramen, Infraorbital nerve, Infraorbital vessels, Face.

Address for Correspondence: Dr. Shruthi B.N, Associate Professor of Anatomy, Rajarajeswari Medical College and Hospital, Bangalore, Karnataka, India.Mobile: +91-9686530303

E-Mail: drshruthibn@yahoo.co.in

\section{Access this Article online}

\section{Quick Response code}

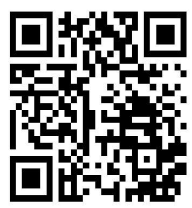

DOI: $10.16965 /$ ijar.2017.300
Web site: International Journal of Anatomy and Research

ISSN 2321-4287

www.ijmhr.org/ijar.htm
Received: 16 June 2017

Peer Review: 16 June 2017

Revised: None
Accepted: $18 \mathrm{Jul} 2017$

Published (O): 31 Aug 2017

Published (P): 31 Aug 2017

\section{INTRODUCTION}

The infraorbital foramen is located in the maxillary bone. It is the anterior opening of the infraorbital canal, which is the anterior continuation of the infraorbital groove, which course through the floor of the orbit. The canal may reside entirely in the maxillary sinus, suspended from the sinus roof by a mesentery. The foramen's facial surface is superior to the canine fossa and inferior to the lower margin of the orbit. It transmits the infraorbital nerve, a branch of the maxillary division of the trigemi 
nal nerve and infraorbital artery and vein. Within the infraorbital groove, the infraorbital nerve gives off sensory branches to the maxillary sinus and upper teeth, that are posterior superior alveolar nerve, middle superior alveolar nerve, anterior superior alveolar nerve.

The infraorbital foramen is an important landmark in facilitating anaesthetic and surgical interventions of the midface region. The infraorbital nerve block is widely used to accomplish regional anaesthesia during surgeries involving the midface region and paranasal sinuses. Traumatic or iatrogenic injury to the infraorbital neurovascular bundle may result in bleeding and hypoesthesia or paraesthesia or anaesthesia in the region of its supply [1-4].

The nerve block of infraorbital nerves can be used in following cases. The location of the infraorbital foramen determines the orientation of an acupuncture point used in trigeminal neuralgia treatment [5]. The position of the infraorbital foramen helps to locate the infraorbital plexus region which we believe a risk zone during plastic surgery [6]. The location of this foramen determines morphometric variations from reference points to decrease the risk of orbital surgery [7]. The morphometry of this foramen plays an important role during regional block anesthesia techniques of the infraorbital nerve $[8,9]$.

The precise location of the foramen facilitates risk free zygoma fracture surgery [10]. Hence, detailed knowledge of the precise anatomical location and the possible variations of the infraorbital foramen is fundamental to ensure safe and successful regional anaesthesia and to avoid the risk of damaging the neurovascular bundle during surgery in this region.

\section{MATERIALS AND METHODS}

300 dry adult human skulls constituted the material for the present study. The skulls belong to the Department of Anatomy, JJM Medical College, Davangere, Rajarajeswari Medical college, Bangalore and Gadag govt medical college, Gadag, Karnataka, India. Each was studied for the morphometric analysis of Infra orbital foramen position. Each skull examined properly and located infraorbital foramen, measerements were recorded with
Vernier callipers.

\section{RESULTS}

Total 300 skulls were used for this study, the results were the mean distance between the infra orbital foramen and the infra orbital margin was $8.48 \pm 1.92 \mathrm{~mm}$, on right side it was $8.72 \pm 2.16 \mathrm{~mm}$ and $8.20 \pm 1.92 \mathrm{~mm}$ on left. The mean distance between the infra orbital foramen and the piriform aperture was $19.35 \pm 3.26 \mathrm{~mm}$, on right side it was $19.10 \pm 3.42$ $\mathrm{mm}$ and $19.56 \pm 3.26 \mathrm{~mm}$ on left. The mean distance between infra orbital foramen and the anterior nasal spine on right was $34.86 \pm 6.73 \mathrm{~mm}$ and left was $36.12 \pm 3.72 \mathrm{~mm}$ and total average was $35.51 \pm 3.75 \mathrm{~mm}$. The transverse diameter was $3.16 \pm 0.96 \mathrm{~mm}$ and vertical diameter was $3.03 \pm 0.72 \mathrm{~mm}$ (Table $1 \& 2$ ).

Table 1: The mean distances between Infra orbital foramen and various reference points.

\begin{tabular}{|c|c|c|c|}
\hline $\begin{array}{c}\text { Distances } \\
\text { between }\end{array}$ & Right side & Left side & Total \\
\hline IOF - IOM & $8.72 \pm 2.16 \mathrm{~mm}$ & $8.20 \pm 1.92 \mathrm{~mm}$ & $8.48 \pm 1.92 \mathrm{~mm}$ \\
\hline IOF - PA & $19.10 \pm 3.42 \mathrm{~mm}$ & $19.56 \pm 3.26 \mathrm{~mm}$ & $19.35 \pm 3.26 \mathrm{~mm}$ \\
\hline IOF - ANS & $34.86 \pm 6.73 \mathrm{~mm}$ & $36.12+3.72 \mathrm{~mm}$ & $35.51+3.75 \mathrm{~mm}$ \\
\hline
\end{tabular}

IOF - Infra orbital foramen, IOM - Infraorbital margin, ANS- Anaterior nasal spine, PA- Piriform aperture.

Table 2: Transverse Diameter and Vertical diameter of Infra orbital foramen.

\begin{tabular}{|c|c|}
\hline \multicolumn{2}{|c|}{ Measurement of IOF } \\
\hline Transverse Diameter & $3.16 \pm 0.96 \mathrm{~mm}$ \\
\hline Vertical diameter & $3.03 \pm 0.72 \mathrm{~mm}$ \\
\hline
\end{tabular}

\section{CONCLUSION}

The Infra orbital foramen is the way to the infraorbital nerve, vessels and the knowledge of its position is very useful to the professionals who manipulate the maxilar region like in acupuncture, zygoma's frature surgery, practical of intra and extra oral anesthesia[10]. The dentist and surgeons of head and neck have to know the exactly position of Infra orbital formen, because the anesthetic must be put on the foramen in order that it diffuses by the canal and causes the anterior superior alveolar nerve block and in consequence, the block of the branches that supply the central superior incisive teeth, lateral incisive and superior canine, ipsilateral to the blocked nerve[11].

Figun [12] point out that, the topography of 
Infra orbital foramen presents unquestionable interesting on the anesthesia practice of alveolar anterior superior nerve and the infraorbital branch, because the foramen is an excellent reference point to intraoral functions and extra oral, 5 to $7 \mathrm{~mm}$ inferior to the infra orbital margin, this is in correlation with our present study observation that is $8.48 \pm 1.92 \mathrm{~mm}$, some more previous studies were recorded same measurement which are having similar findings as our present study. Dubrul[13] reported about the variable distance between 6 to $8 \mathrm{~mm}$ under the inferior margin of the orbit. Bergman et al[14] describe a bigger variation, between 3 to $7 \mathrm{~mm}$ inferior to the infra orbital margin. Karakas et al[15] pointed that the measurement between the Infra orbital foramen and midpoint of the inferior orbital margin was taken as $7 \mathrm{~mm}$. The present study was reported that mean distance between infraorbitol foramen and anterior nasal spine was $35.51 \pm 3.75 \mathrm{~mm}$, this findings are in correlation with previous studies $[16,17]$. In another study also reported slight higher results than present study in Indian population [1]. The mean distance of the infraorbital foramen from the piriform aperture was $19.35 \pm 3.26 \mathrm{~mm}$, which was close to some previous studies record. Rajani Singh[18] was repoted15.56, Kazkayasi et al[19] reported $14.70 \mathrm{~mm}$.

According to the literature there are some standards of location of the foramen on the surface ${ }_{2}$ one of them is to check the line that joins the gengival margin, situated between the central and lateral incisive, medial to the frontozigomatic suture, a reference point easily recognized $4 \mathrm{~mm}$ over a horizontal line that passes by the lateral angle of eyelid slit. Another classic conduct suggests situate the foramen on a vertical line that joins the supraorbital incisure to the mentonian foramen, 5 to $6 \mathrm{~mm}$ under the orbital margin. Information on skull foramina size and symmetry is increasingly important because of the advancements in radiologic techniques such as magnetic resonance imaging and computed tomography. These methods are making difficult diagnoses of pathologic conditions of skull foramina possible[13, 20].

The importance of the incidence and lateralization of the Infra orbital foramen is also evident in facial surgical procedures. The recognition of the presence of double or triple foramens is essential when the appropriate amount of anesthesia is applied, or it can be inappropriate. The study of the Infra orbital foramen is also basic to prevent the potential risk for iatrogenic injury during facial surgeries due to the presence of additional branches of the infra orbital nerve[19]. Previous studies show the relation between infra orbital foramen and the other anatomical structures, in studies with different purposes, what shows its importance as a repair point: distance between infra orbital foramen and an imaginary horizontal line in the piriform aperture base, inferior orbital fissure and the more inferior portion of the optical channel[21] medium facial line on an imaginary line that passes through the supraorbital incisure; eyes pupil and second premolars[22] medium sagittal plane and supraorbital incisures[23] and finally related to the piriform aperture[19]. The morphometric and morphological studies of foramens of skull and different bones of skull are more helpful in surgery practice and anthropometric studies[24, 25]. The present study results of infraorbital foramen morphometric measurements may be helpful in facial and dental surgery practice.

\section{Conflicts of Interests: None}

\section{REFERENCES}

[1]. Deepthi Nanayakkara, Roshan Peiris, Navini Mannapperuma, Amal Vadysinghe. Morphometric Analysis of the Infraorbital Foramen: The Clinical Relevance. Anatomy Research International. Volume 2016, Article ID 7917343. http://dx.doi.org/10.1155/ 2016/7917343.

[2]. Aziz S R, J. M. Marchena, and A. Puran. Anatomic characteristics of the infraorbital foramen: A Cadaver Study. Journal of Oral and Maxillofacial Surgery, 2000;58(9):992-996.

[3]. Chandra R. K, Kennedy D. W. Surgical implications of an unusual anomaly of the infraorbital nerve. Ear, Nose and Throat Journal,vol.83,no.11,pp.766767,2004.

[4]. Shaik HS, Shepur MP, Desai SD, Thomas ST, Maavishettar GF, Haseena S. Study of mastoid canals and grooves in South Indian skulls. Indian J Med Healthc 2012;1:32-33.

[5]. Esper RS, Yara J, Yamamura Y, Cricenti SV. RelaçÕes anatômicas do ponto de acupuntura E-2 (Sibai) localizado no forame infraorbital. Rev Paul Acupunt. 1998;4:19-21. 
[6]. Hwang K, Han JY, Battuvshi n D, Ki m DJ, Chung IH. Communication of infraorbital nerve and facial nerve: anatomic and histologic study. J Craniofac Surg 2004;15:88-91.

[7]. Karakas P, Bozkir MG, Oguz O. Morphometric measurements from various reference points in the orbit of male Caucasians. Surg Radiol Anat 2003;24:358-62.

[8]. Chung MS, Kim HJ, Kang HS, Chung IH. Locational relationship of the supraorbital notch or foramen and infraorbital and mental foramina in Koreans. Acta Anat (Basel) 1995;154:162-6.

[9]. Radwan IA, Saito S, Goto F. High-concentration tetracaine for the management of rigeminal neuralgia: quantitative assessment of sensory function after peripheral nerve block. Clin J Pain 2001;17:323-6.

[10]. Du Tolt DF, Nortjé C. The maxillae: integrated and applied anatomy relevant to dentistry. SADJ 2003;58:325-30.

[11]. Zide B, and Swift R. How to block and tackle the face. Plast. Reconstr. Surg., 1998;101:2018.

[12]. Figun, ME, Garino R. Anatomia odontologica functional E aplicada. Sao paulo, panamericana. 1994.

[13]. Dubrul EL, Sicher and Dubrul oral anatomy. 8th ed. Ishiyaku euroamerica publishers. 1991.

[14]. Bergman RA, Thompson SA, Afifi AK, Saadeh FA. Compendium of human anatomic variation: catalog, Atlas and world literature. Baltimore. Urban \& Schwarzenberg. 1998.

[15]. Karakas P, Bozkir M.G, Oguz O. Morphometric measurements from various reference points in the orbit of male caucasians. Surg. Radiol. Anat. 2002;24(6), 358-62.

[16]. Pzygocka. A, Podg orski, K. Jedrzejewski, M. Topol, and $M$. Polguj. The location of the infraorbital foramen in human skulls, to be used as new anthropometric landmarks as a useful method for maxillofacial surgery. Folia Morphologica. 2002:7(2):198204.
[17]. Singh, A., P. Agarwal, N. Singh, and S. Debberma. Accessory infraorbital foramen and Morphometric localization of infraorbital foramen. National Journal of Integrated Research and Medicine. 2015;6(5):28-33.

[18]. Rajani Singh. Morphometric analysis of infraorbital foramen in Indian dry skulls. Anat Cell Biol 2011;44:79-83. doi: 10.5115/acb.2011.44.1.79.

[19]. Kazkayasi M, Ergin A, Ersoy M et al. A Microscopic anatomy of the infra orbital canal, nerve, and foramen. Otolaryngology - Head \& neck surgery. 2003;129(6):692-697.

[20]. Berge JK, Bergman RA. Variations in size and in symmetry of foramina of the human skull. Clinical anatomy. 2001;14(6):406-413.

[21]. Rontal E, Rontal M, Guilford F T. Surgical anatomy of the orbit. Ann. Otol.1979;88:382-6.

[22]. Molliex S, Navez M and Baylot D. Regional anesthesia for outpatient nasal surgery. British journal of anaesthesia. 1996;76:(1) 151-153.

[23]. Chung MS, Kim HJ, Kang HS, Chung IH. Locational relationship of the supraorbital notch or foramen and infraorbital and mental foramina in Koreans. Acta anat. 1995:154:162-6.

[24]. Saheb HS, Mavishetter GF, Thomas ST, Prasanna LC, Muralidhar P. Occipitalization of Atlas: A case report. J. Biomedsci and Res. 2010;2:73-75.

[25].Hussain Saheb S, Mavishettar GF, Thomas ST, Prasanna LC. Incidence of metopic suture in adult south Indian skulls. J Biomed Sci Res 2010;2:223-6.

How to cite this article:

Shaik Hussain Saheb, Shruthi B.N, Pavan P Havaldar. A STUDY

ON POSITION OF INFRAORBITAL FORAMEN. Int J Anat Res

2017;5(3.2):4257-4260. DOI: 10.16965/ijar.2017.300 